University of Nebraska - Lincoln

DigitalCommons@University of Nebraska - Lincoln

Library Philosophy and Practice (e-journal)

Libraries at University of Nebraska-Lincoln

Fall 10-1-2020

\title{
Road Traffic Accident Research in India: A Scientometric Study from 1977 to 2020
}

Dr. Jayaprakash G. Hugar

Dnyanprassarak Mandal's College and Research Centre, Assagao, Mapusa - 403 507, Goa, India

Dr. Mirza Muhammad Naseer

Imam Abdulrahman Bin Faisal University, mmnaseer@iau.edu.sa

Dr. Abu Waris

Imam Abdulrahman Bin Faisal University

Muhammad Ajmal Khan

Imam Abdulrahman Bin Faisal University, makhan@iau.edu.sa

Follow this and additional works at: https://digitalcommons.unl.edu/libphilprac

Part of the Health Sciences and Medical Librarianship Commons, Scholarly Communication Commons, Scholarly Publishing Commons, and the Transportation Commons

Hugar, Dr. Jayaprakash G.; Naseer, Dr. Mirza Muhammad; Waris, Dr. Abu; and Khan, Muhammad Ajmal, "Road Traffic Accident Research in India: A Scientometric Study from 1977 to 2020" (2020). Library Philosophy and Practice (e-journal). 4325.

https://digitalcommons.unl.edu/libphilprac/4325 


\title{
Road Traffic Accident Research in India: A Scientometric Study from 1977 to 2020
}

\author{
Dr. Jayaprakash G. Hugar \\ Dnyanprassarak Mandal's College and Research Centre, Assagao, Bardez, Mapusa, Goa, India. \\ dmclibrarian@rediffmail.com \\ Dr. Mirza Muhammad Naseer \\ Deanship of Library Affairs, Imam Abdulrahman Bin Faisal University, Kingdom of Saudi Arabia. \\ mmnaseer@iau.edu.sa
}

Dr. Abu Waris

Deanship of Library Affairs, Imam Abdulrahman Bin Faisal University, Kingdom of Saudi Arabia. abuwaris@iau.edu.sa

Muhammad Ajmal Khan

Deanship of Library Affairs, Imam Abdulrahman Bin Faisal University, Kingdom of Saudi Arabia. makhan@iau.edu.sa

\begin{abstract}
:
This study carried out the scientometric analysis of road traffic accident research in India from 1977 to 2020. It aimed to examine type of publications with their citations and usage, the year wise publication and citation growth, most preferred journals, authors' preference of keywords used, collaboration of Indian authors, authorship pattern and most prolific authors, and top contributing organizations. During 44 years of study, 1,132 research items were published and indexed in Web of Science (WoS) bibliographic database. Analysis discovered that number of publications increased from one $(0.08 \%)$ in 1977 to $182(16.07 \%)$ in 2018 and observed good progress in scholarly literature.

Majority of scholarly publications were published in the form of article $(740,65.37 \%)$. From 2006 to 2018, number of publications increased rapidly from $11(0.97 \%)$ to $182(16.07 \%)$ publications, which was the most productive year for the researchers. On an average 25.73 documents were published per year and received 392.95 citations per year. Journal of Evaluation
\end{abstract}


of Medical and Dental Sciences published majority of the publications (108, 30.50\%). The word "Trauma" was the most frequently used keyword. Majority of publications (83.38\%) on road traffic accidents (RTA) were written by the Indian authors individually or with local collaboration. Majority of the publications $(1,081,95.49 \%)$ were written by multiple authors while 51 publications (4.51\%) were from single author. Most prolific authors were Tiwari, G. and Mohan, D. with 18 publications each. The Indian Institute of Technology was highly contributing organization, which published 120 documents (10.60\%).

Keywords: Scientometric, Scholarly publications, Web of Science, Traffic Accidents, Road Safety, India.

Introduction

The term accident has been defined as an occurrence in a sequence of events which usually produces unintended injury, death, or property damage. Today accidents are among the leading causes of death. Deaths due to Road Traffic Accidents (RTA) are increasing at an alarming rate throughout the world. Fifty years ago, the World Health Organization (WHO) was called upon to do something about the heavy human toll of road traffic injuries. However, RTAs remain a very significant contributor to human morbidity and mortality. It is significant to note that the burden of RTAs has shifted to low and middle income countries (LMICs), which despite having only about $50 \%$ of the world's motor vehicles, account for $90 \%$ of the burden of 12.5 lakh road traffic deaths and two to five crore non-fatal road traffic injuries (Lena, et al., 2019). Road traffic fatalities constitute $16.6 \%$ of all deaths, making this the sixth leading cause of death in India, and a major contributor to socio-economic losses, the disability burden, and hospitalization. The financial burden is particularly high for poorer households in rural areas and those seeking treatment at 
private health facilities with no health insurance. The road accidents are frequent in occurrence and a leading cause of death in India (Goli, Shruti, Siddiqui, \& Gouda, 2018).

Amongst all traffic accidents, road traffic accidents claim largest toll of human life and tend to be the most serious problem world over. Worldwide, the number of people killed in road traffic accidents (RTA) each year is estimated at almost 1.2 million, while the number of injured could be as high as 50 million (Pathak, Gadhari, Chaudhari, \& Devraj, 2018). In India, road traffic injuries will be the third leading cause of death by 2020 . These figures will increase by as much as 80 per cent over the next 20 years in low- and middle-income countries unless there is a new commitment to prevention (World Health Organisation, 2004). By 2020, road deaths and injuries are predicted to be the third leading contributor to the global burden of disease and injury (Murray \& Lopez, 1996). There will be a death every 23 seconds, 43,640 monthly and 7,22,917 in a year in the world. Road deaths per thousand is highest in South East Asia in the world. The number of road traffic deaths continues to rise steadily. However, the rate of death relative to the size of the world's population has remained constant.

The Global status report on road safety 2013 estimates that more than 231,000 people are killed in road traffic crashes in India every year (World Health Organisation, 2013). Approximately half of all deaths on the country's roads are among vulnerable road users motorcyclists, pedestrians, and cyclists. A heterogeneous traffic mix that includes high-speed vehicles sharing the road space with vulnerable road users as well as unsafe road infrastructure and vehicles that are in poor condition all contribute to the high fatality rates seen on India's roads (World Health Organisation, 2018). 


\section{Literature Review}

Shami (2005) reported that every year more than seven million Indians suffered in traffic accidents from simple injuries to serious accidents and deaths. Most of those who suffer were from the group of vulnerable road user's i.e. pedestrians and cyclists. Yet, traffic campaigns focused on the smooth flow of traffic and priorities of four-wheel vehicle drivers. The annual cost of traffic accidents to India stood at close to 2 per cent of GDP, which was an unacceptably high burden. An informed and multi-sectoral approach backed by strong willed commitment to reducing traffic accidents could bring about a substantial difference. The study by Sundar and Ghate (2013) supported the study of Shami (2005) and conveyed that among all countries, India had the highest number of deaths due to road traffic-related accidents. Road accidents were the sixth leading cause of death in the country and there were nearly 1,40,000 deaths from road accidents in 2012. Despite being a major public health issue that affects the most vulnerable and the most productive sections of society, road safety had not received the attention it deserved. Further, they discussed about how the government had not recognized road safety as a key mobility, health, and equity issue, and had been slow in enacting legislation to establish the institutional mechanisms to promote road safety.

Singh (2009) reported that the road traffic injuries and deaths were a hidden epidemic in the cities of Uttar Pradesh (UP) province. With one exception, they had the highest road accident fatalities in India. Despite that, road safety was not a political priority in UP. The state, as well as local governments, should curtail traffic accidents through road safety education and enforcement and mediate the outcome of accidents by designing safe roads with affordable and cost-effective measures. Shobhana, Raviraj, Yadav and Kumar (2019) found that one of the common regional injuries an individual can sustain in Road Traffic Accidents was head injury. Head and face was 
the region which was more susceptible and required an immediate care and treatment. The fatality rate was high even with intense treatment. Law making agencies had been continuously trying to enforce the rules of wearing helmets both in riders and pillion in two wheelers. Considering the same, the study was done in eastern part of Bangalore, an IT hub, and a rapidly developing area with increase in vehicular movements. The study concluded that incidence was common among age group of 21-30 years with male predominance and among two-wheel riders. Laceration was most common external injury followed by abrasion. Fissure fractures were most common type of fracture and subdural hemorrhage was seen in majority of cases.

Very few scientometrics studies have been conducted on Road Traffic Accidents in India and those too with a limited scope. For example, analysis road traffic injuries research in India by Sharma, Bairwa, Gowthamghosh, Gupta and Mangal (2018), covering literature published between 1991 and 2017, revealed that most frequently used words were traffic accident, male, youngster, and adolescent. The highly contributed authors were Gururaj G, Dandona, R and Hyder AA. The main sources of RTA publications were the Indian Journal of Forensic Medicine and Toxicology, the Medico Legal Update, and the International Journal of Advanced Engineering Research. Highly contributing organizations were the All India Institute of Medical Sciences, New Delhi, the Indian Institute of Technology, Delhi, and the Indian Administrative Staff College. Ruikar (2013) declared his analysis as bibliometric but missed all key bibliometric indicators. He reported that India, the second most densely populated country in the world, had contributed only $0.7 \%$ research on road traffic injuries, which corresponds to less than one article on per 1000 road traffic deaths. The literature lacked a comprehensive scientometric study on the Road Traffic Accidents in India. Therefore, the authors selected 44 years' Web of Science data in this area for the study purpose. 


\section{Objectives}

1. To explore the type of publications on RTA with their citations and usage

2. To identify the year wise publication and citation growth on RTA

3. To recognize the journals preferred for RTA research

4. To know the preference of keywords used in RTA publications

5. To find out the collaboration of authors involved in RTA research

6. To realize the authorship pattern and most prolific authors in RTA literature

7. To explorer the top contributing organizations in RTA research

\section{Methodology}

The Scientometric study covered all research publications indexed in Clarivate analyticsWeb of Science (WoS) database on Road Traffic Accidents, which had India in the address field. It accessed the contributions on "Road Safety", "Road Injury", "Traffic Accident" and other related areas. The bibliographic data on the topic was retrieved from WoS on $23^{\text {rd }}$ January 2020, without any limit on timespan, using the following search query.

TS=("road safety*" OR "road Injury*" OR "traffic accident*" OR "vehicle accident*" OR "road trauma*" OR "road casualty*" OR "traffic casualty*" OR "traffic safety*" OR "traffic

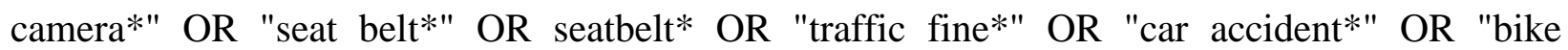
Accident*" OR "motorbike accident*" OR "motorcycle Accident*" OR "motorcycle crash*" OR airbag* OR "Air Bag*" OR "road fatality*" OR "child restraint" OR "Road Death*" OR "traffic enforcement" OR "pedestrian safety" OR "Road Crash*") AND AD=(India)

Timespan: All years. Indexes: SCI-EXPANDED, SSCI, A\&HCI, CPCI-S, CPCI-SSH, ESCI, CCR-EXPANDED, IC. 
During the data retrieval, the researchers used the advanced search option of the WoS database and retrieved 1,176 research publications. Duplicate $(\mathrm{n}=2)$ and irrelevant $(\mathrm{n}=5)$ records were not included in the analysis. Similarly, records having document type as Note $(\mathrm{n}=3)$, Letter $(\mathrm{n}=4)$, Correction $(\mathrm{n}=1)$, Editorial material $(\mathrm{n}=15)$, and Meeting abstract $(\mathrm{n}=14)$ were not included in the analysis. After careful examination of the retrieved data, 1,132 records were included in the analysis. The data downloaded were analyzed for different parameters like type of documents, citations, and usage; year wise publication and citation growth; top source journals, preference of keywords used; collaborating countries; authorship pattern and most prolific authors; and top contributing organizations. The data were analyzed using MS-Access and MS-Excel while visualization of co-occurrence of keywords used was drawn using VOS viewer. This study was limited to publications related to the Road Traffic Accidents, which were indexed in WoS up to January 23, 2020 and had India in their address field. Therefore, scholars should consider the results of this study in the light of these limitations.

\section{Data analysis and interpretation}

Table 1 indicated that out of 1,132 publications, $740(65.37 \%)$ publications were in the form of research articles, $361(31.82 \%)$ publications were in the form of proceeding papers, and 31 (2.73\%) publications were in the reviews form. Articles got highest citations $(16,111,93.18 \%)$,

reviews got $664(3.84 \%)$ citations, and conference proceeding papers got only $515(2.97 \%)$ citations. Whereas, 7,061 articles (87.99\%), 492 reviews (6.13\%), and 471 proceeding papers (5.86\%) were used since 2013. Overall, usage and citations of articles were more as compared to other two forms of publications on the study topic. 
Table 1

Distribution of publication types, citations, and usage

\begin{tabular}{lrrrrrr}
\hline $\begin{array}{l}\text { Publication } \\
\text { Types }\end{array}$ & $\begin{array}{r}\text { Publications } \\
\text { Count }\end{array}$ & Percentage & $\begin{array}{r}\text { Citation } \\
\text { Count }\end{array}$ & & $\begin{array}{r}\text { Usage } \\
\text { since 2013 }\end{array}$ & \\
\hline Article & 740 & 65.37 & 16,111 & 93.18 & 7,061 & 87.99 \\
Proceeding Paper & 361 & 31.82 & 515 & 2.97 & 471 & 5.86 \\
Review & 31 & 2.73 & 664 & 3.84 & 492 & 6.13 \\
\hline Total & $\mathbf{1 , 1 3 2}$ & $\mathbf{1 0 0 . 0 0}$ & $\mathbf{1 7 , 2 9 0}$ & $\mathbf{1 0 0 . 0 0}$ & $\mathbf{8 , 0 2 4}$ & $\mathbf{1 0 0 . 0 0}$ \\
\hline
\end{tabular}

Citations are important for researchers to know the popularity and impact of their publications in the scholarly society. Table 2 showed the year wise distribution of publications, citations, and usage from 1977 to 2020 . Analysis disclosed that first publication on RTA in India, which was indexed in WoS, appeared in the year 1977. There was no publication indexed in WoS database from the year 1979 to 1991 and in the year 1998 according to the scope of the study. During the 44 years of study period, 1,132 documents were indexed in WoS. In the first 29 years (from 1977 to 2005) only 58 documents were published and received 647 citations. In next fifteen years (from 2006 to 2020), 1,074 documents were published, which received 16,643 citations. On an average 25.73 documents per year were published, which received 392.95 citations per year during the study period. Highest usage of these publications was made in the year $2012(3,949$, 49.19\%), followed by 1,004 (12.50\%) and 991 (12.34\%) in the years 2018 and 2016, respectively. Likewise, the publications analyzed received majority of citations in the year $2012(11,702$, $67.68 \%)$ followed by $1,070(6.18 \%)$ and 1,070 (6.18\%) in 2016 and 2007, respectively. For the remaining years, usage and citations were very low or non-existent. It showed that there was huge difference in usage and citation of the publications in different years. 
Table 2

Year wise distribution of publications, citations, and usage

\begin{tabular}{|c|c|c|c|c|c|c|}
\hline Year & $\begin{array}{r}\text { Publication } \\
\text { Count }\end{array}$ & Percentage & $\begin{array}{r}\text { Citation } \\
\text { Count }\end{array}$ & Percentage & $\begin{array}{r}\text { Usage since } \\
2013\end{array}$ & Percentage \\
\hline 1977 & 1 & 0.08 & 0 & 0.00 & 0 & 0.00 \\
\hline 1978 & 1 & 0.08 & 3 & 0.01 & 0 & 0.00 \\
\hline 1992 & 1 & 0.08 & 0 & 0.00 & 0 & 0.00 \\
\hline 1993 & 1 & 0.08 & 30 & 0.17 & 0 & 0.00 \\
\hline 1994 & 2 & 0.17 & 37 & 0.21 & 5 & 0.06 \\
\hline 1995 & 3 & 0.26 & 12 & 0.06 & 1 & 0.01 \\
\hline 1996 & 2 & 0.17 & 19 & 0.10 & 0 & 0.00 \\
\hline 1997 & 3 & 0.26 & 86 & 0.49 & 0 & 0.00 \\
\hline 1999 & 6 & 0.53 & 52 & 0.30 & 3 & 0.03 \\
\hline 2000 & 9 & 0.79 & 99 & 0.57 & 11 & 0.13 \\
\hline 2001 & 5 & 0.44 & 35 & 0.20 & 7 & 0.08 \\
\hline 2002 & 4 & 0.35 & 119 & 0.68 & 16 & 0.19 \\
\hline 2003 & 6 & 0.53 & 68 & 0.39 & 11 & 0.13 \\
\hline 2004 & 7 & 0.61 & 21 & 0.12 & 5 & 0.06 \\
\hline 2005 & 7 & 0.61 & 66 & 0.38 & 5 & 0.06 \\
\hline 2006 & 11 & 0.97 & 155 & 0.89 & 48 & 0.59 \\
\hline 2007 & 14 & 1.23 & 1,056 & 6.10 & 161 & 2.00 \\
\hline 2008 & 27 & 2.38 & 364 & 2.10 & 74 & 0.92 \\
\hline 2009 & 29 & 2.56 & 218 & 1.26 & 43 & 0.53 \\
\hline 2010 & 15 & 1.32 & 34 & 0.19 & 25 & 0.31 \\
\hline 2011 & 23 & 2.03 & 133 & 0.76 & 65 & 0.80 \\
\hline 2012 & 36 & 3.18 & 11,702 & 67.68 & 3,949 & 49.19 \\
\hline 2013 & 46 & 4.06 & 230 & 1.33 & 210 & 2.61 \\
\hline 2014 & 53 & 4.68 & 328 & 1.89 & 187 & 2.32 \\
\hline 2015 & 169 & 14.92 & 347 & 2.00 & 306 & 3.81 \\
\hline 2016 & 182 & 16.07 & 1,070 & 6.18 & 991 & 12.34 \\
\hline 2017 & 165 & 14.57 & 281 & 1.62 & 546 & 6.80 \\
\hline 2018 & 182 & 16.07 & 677 & 3.91 & 1,004 & 12.50 \\
\hline 2019 & 116 & 10.24 & 43 & 0.24 & 338 & 4.21 \\
\hline $2020^{*}$ & 6 & 0.53 & 5 & 0.02 & 17 & 0.21 \\
\hline Total & 1,132 & 100.00 & 17,290 & 100.00 & 8,024 & 100.00 \\
\hline
\end{tabular}

* Data up to January 23, 2020 
Table 3 disclosed that number of papers published by different journals on RTA. Journal of Evaluation of Medical and Dental Sciences (JEMDS) ranked first in the list for publishing 108 (30.50\%) papers, followed by Journal of Clinical and Diagnostic Research and International Journal of Scientific Study, which published 28 (7.90\%) and 24 (6.77\%) papers respectively. There was a huge gap between the first and second rank journal in number of publications. Journal of Evolution of Medical and Dental Sciences was publishing more papers on RTA whereas the papers published in Lancet journal on RTA were more used $(3,993)$ and obtained majority of citations $(11,758,94.04 \%)$. It showed the popularity and high-quality of research published in the Lancet journal. The Accident Analysis and Prevention and Transportation Research Record got second and third rank respectively in the usage during the study period.

\section{Table 3}

Top 20 journals preferred for RTA research

\begin{tabular}{|c|c|c|c|c|c|c|}
\hline Journals & $\begin{array}{l}\text { Public } \\
\text { ations }\end{array}$ & $\begin{array}{r}\text { Percentage } \\
\text { of total } \\
\text { publications }\end{array}$ & $\begin{array}{r}\text { Citation } \\
\text { count }\end{array}$ & $\begin{array}{r}\text { Percentage } \\
\text { of total } \\
\text { citations }\end{array}$ & $\begin{array}{r}\text { Usage } \\
\text { since } \\
2013\end{array}$ & $\begin{array}{r}\text { Usage } \\
\text { rank }\end{array}$ \\
\hline $\begin{array}{l}\text { Journal of Evolution of } \\
\text { Medical and Dental } \\
\text { Sciences-JEMDS }\end{array}$ & 108 & 30.50 & 12 & 0.09 & 73 & 4 \\
\hline $\begin{array}{l}\text { Journal of Clinical and } \\
\text { Diagnostic Research }\end{array}$ & 28 & 7.90 & 26 & 0.20 & 19 & 14 \\
\hline $\begin{array}{l}\text { International Journal of } \\
\text { Scientific Study }\end{array}$ & 24 & 6.77 & 5 & 0.03 & 5 & 19 \\
\hline $\begin{array}{l}\text { International Journal of } \\
\text { Injury Control and Safety } \\
\text { Promotion }\end{array}$ & 21 & 5.93 & 31 & 0.24 & 38 & 9 \\
\hline Injury Prevention & 17 & 4.80 & 128 & 1.02 & 65 & 5 \\
\hline $\begin{array}{l}\text { Journal of Maxillofacial \& } \\
\text { Oral Surgery }\end{array}$ & 15 & 4.23 & 51 & 0.40 & 24 & 11 \\
\hline
\end{tabular}


Indian Journal of

Orthopedics

Accident Analysis and

Prevention

Indian Journal of

Neurotrauma

Medicine Science and the

Law

Indian Journal of Surgery

International Journal of

Crashworthiness

Journal of Forensic and

Legal Medicine

Indian Journal of

Community Health

Indian Journal of

Otolaryngology and Head \&

Neck Surgery

Lancet

Research Journal of

Pharmaceutical Biological

and Chemical Sciences

Traffic Injury Prevention

Transportation Research

Record

Current Science
14

12

12

11

10

10

10

9

9

9

9

2.5

2.54

9

9

8

3.95

3.38

3.38

3.10

2.82

2.82

2.82

2.54

2.54

2.54

.

2.54

2.54

2.25
10

20

17

75

3

0.02

0.07

0.13

0.13

0.59

47

8

16

11,758

0

$94.04 \quad 3,993$

0.00

7

17
Figure 1 displayed the co-occurrence network of keywords used in RTA publications. In this study, keyword Trauma was more used (20\%) by RTA authors in various papers published during the study period, followed by Vehicular Ad hoc Networks and Road Traffic Accidents with $16.66 \%$ and $15 \%$ use, respectively. The density of the term reflected the number of related keywords in various documents in which both were found. The gap between two terms offered an 


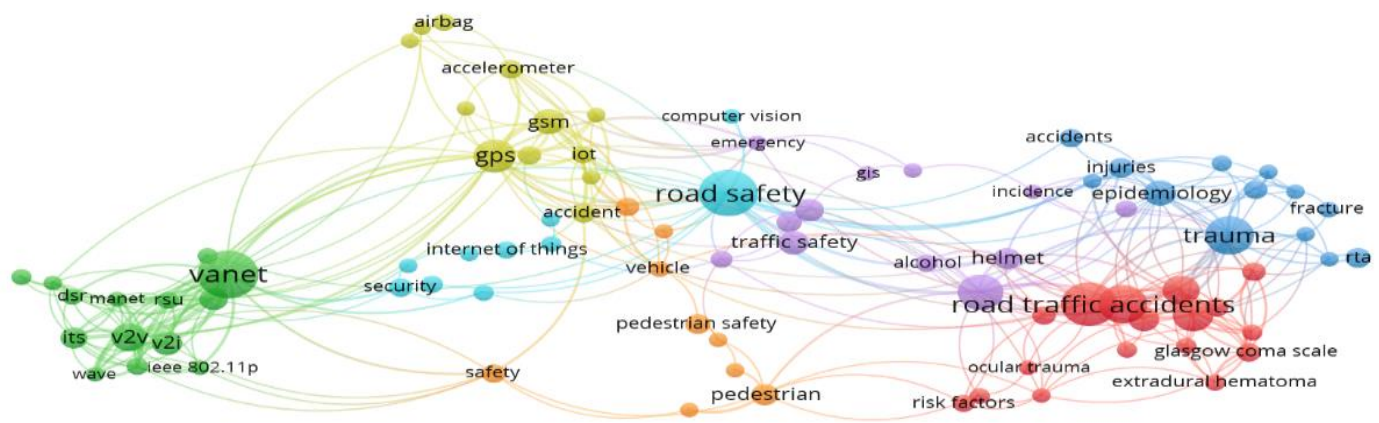

for vosviewer

Figure 1: Keyword co-occurrence network

Table 4

Collaboration of Indian RTA authors

\begin{tabular}{lrr}
\hline Country & $\begin{array}{r}\text { Country } \\
\text { Occurrences }\end{array}$ & $\begin{array}{r}\text { Percentage of } \\
\text { Occurrences }\end{array}$ \\
\hline India & 1,174 & 83.38 \\
USA & 75 & 5.32 \\
England & 31 & 2.20 \\
Australia & 25 & 1.77 \\
Peoples R China & 18 & 1.27 \\
Canada & 16 & 1.13 \\
South Korea & 15 & 1.06 \\
Germany & 14 & 0.99 \\
Japan & 14 & 0.99 \\
Brazil & 13 & 0.92 \\
Saudi Arabia & 13 & 0.92 \\
\hline
\end{tabular}


approximate indication of the relatedness of terms. The relatedness of terms resolved supported co-occurrences. Different colors represented groups of terms that were strongly associated with each other.

Analysis of author collaboration based on their affiliations has been presented in Table 4 . Collaboration plays an important role in writing any scholarly publication. In this study, the Indian authors wrote majority of the papers individually or with local collaboration (83.38\% occurrences). The authors writing on RTA had highest collaboration with United States (5.32\%) and United Kingdom (2.20\%). Contributions of remaining countries, such as Australia, China, Canada, South Korea, Germany, Japan, Brazil, and Saudi Arabia, were very low (from $1.77 \%$ to $0.92 \%$ ). Moreover, it revealed that majority of authors writing on RTA in India collaborated with local authors during the study period.

Table 5

Authorship pattern

\begin{tabular}{lrr}
\hline Authors & Publications & $\begin{array}{r}\text { Percentage of } \\
\text { Publications }\end{array}$ \\
\hline Single Author & 51 & 4.51 \\
Two Authors & 300 & 26.50 \\
Three Authors & 260 & 22.97 \\
Four Authors & 213 & 18.82 \\
Five Authors & 120 & 10.60 \\
Six Authors & 102 & 9.01 \\
Seven Authors & 31 & 2.74 \\
Eight Authors & 23 & 2.03 \\
Nine Authors & 7 & 0.62 \\
Ten or More Authors & 25 & 2.21 \\
\hline Total & $\mathbf{1 , 1 3 2}$ & $\mathbf{1 0 0 . 0 0}$ \\
\hline
\end{tabular}


When we collaborate with each other, there will be several authors involved in writing research publications instead of single author. Table 5 displayed the authorship pattern. It revealed that highest number of publications $(300,26.50 \%)$ were written by two authors, followed by three authors $(260,22.97 \%)$, and four authors $(213,18.82 \%)$. Majority of the publications $(1,081$, $95.49 \%$ ) on RTA were multi-authored while only $4.51 \%$ (51) were single authored. A small number of publications $(7,0.62 \%)$ was written by nine authors, whereas ten or more authors published $25(2.21 \%)$ papers. It indicated the trend towards multi-authored publications.

\section{Table 6}

Top 10 most prolific authors

\begin{tabular}{|c|c|c|c|c|c|c|}
\hline $\begin{array}{l}\text { Productivity } \\
\text { Rank }\end{array}$ & Authors & Publications & Citations & $\begin{array}{r}\text { Citation } \\
\text { Rank }\end{array}$ & $\begin{array}{r}\text { Usage } \\
\text { since } 2013\end{array}$ & $\begin{array}{l}\text { Usage } \\
\text { Rank }\end{array}$ \\
\hline 1 & Tiwari, G & 18 & 252 & 3 & 213 & 1 \\
\hline 1 & Mohan, D & 18 & 247 & 4 & 144 & 3 \\
\hline 3 & Vedagiri, $\mathrm{P}$ & 13 & 72 & 5 & 119 & 4 \\
\hline 4 & Dandona, $\mathrm{R}$ & 11 & 309 & 2 & 111 & 5 \\
\hline 4 & Kumar, R & 11 & 35 & 7 & 45 & 7 \\
\hline 4 & Singh, A & 11 & 8 & 10 & 13 & 9 \\
\hline 7 & Gupta, S & 10 & 26 & 8 & 26 & 8 \\
\hline 7 & Kumar, P & 10 & 19 & 9 & 6 & 10 \\
\hline 9 & Gururaj, G & 8 & 815 & 1 & 154 & 2 \\
\hline 10 & Mitra, S & 7 & 66 & 6 & 92 & 6 \\
\hline
\end{tabular}

Table 6 depicted the productivity of top ten authors. Tiwari, G. from Indian Institute of Technology, New Delhi and Mohan, D. from Jawaharlal Nehru University, Delhi contributed highest number of publications (18 publications each) on Road Traffic Accidents. Gururaj, G. from National Institute of Mental Health and Neurosciences, Bangalore received maximum number of citations (815) from different authors. Publication usage from the year 2013 found that 
publications of Tiwari, G. were used more number of times (213) as compared to other authors. Gururaj, G. published only eight papers and got highest number of citations during the study period. It may be considered that his publications were of high quality and he may be considered as the best author, in qualitative terms, during the study period.

\section{Table 7}

\section{Top 10 contributing organizations}

\begin{tabular}{|c|c|c|c|c|c|c|}
\hline Rank & Organization & $\begin{array}{l}\text { Publications } \\
\text { (Percentage) }\end{array}$ & Citations & $\begin{array}{r}\text { Usage } \\
\text { since } 2013\end{array}$ & $\begin{array}{r}\text { Citations / } \\
\text { Publication }\end{array}$ & $\begin{array}{l}\text { Type of } \\
\text { Institution }\end{array}$ \\
\hline 1 & $\begin{array}{l}\text { Indian Institute of } \\
\text { Technology }\end{array}$ & $120(10.60 \%)$ & 850 & 994 & 7.08 & Government \\
\hline 2 & $\begin{array}{l}\text { All India Institute of } \\
\text { Medical Science }\end{array}$ & $58(5.12 \%)$ & 11,876 & 4,138 & 204.76 & Government \\
\hline 3 & $\begin{array}{l}\text { National Institute } \\
\text { Technology }\end{array}$ & $50(4.42 \%)$ & 200 & 227 & 4.00 & Government \\
\hline 4 & $\begin{array}{l}\text { Vellore Institute of } \\
\text { Technology (VIT) }\end{array}$ & $39(3.45 \%)$ & 5,481 & 1,706 & 140.54 & Private \\
\hline 5 & Manipal University & $31(2.74 \%)$ & 388 & 236 & 12.52 & Private \\
\hline 6 & Anna University, Chennai & $12(1.06 \%)$ & 11 & 13 & 0.92 & Government \\
\hline 7 & $\begin{array}{l}\text { Indian Institute of Science } \\
\text { (IISC) Bangalore }\end{array}$ & $11(0.97 \%)$ & 44 & 59 & 4.00 & Government \\
\hline 8 & $\begin{array}{l}\text { Amrita Vishwa } \\
\text { Vidyapeetham }\end{array}$ & $11(0.97 \%)$ & 8 & 25 & 0.73 & Private \\
\hline 9 & $\begin{array}{l}\text { Post Graduate Institute of } \\
\text { Medical Education } \\
\text { Research (PGIMER) } \\
\text { Chandigarh }\end{array}$ & $10(0.88 \%)$ & 29 & 35 & 2.90 & Government \\
\hline 10 & $\begin{array}{l}\text { Public Health Foundation } \\
\text { of India }\end{array}$ & $9(0.79 \%)$ & 1,029 & 671 & 114.33 & Government \\
\hline
\end{tabular}

Table 7 displayed the top 10 organizations which contributed to the publishing of RTA research. Authors affiliated to Indian Institute of Technology contributed to $120(10.60 \%)$ publications and thus stood at the first place. All India Institute of Medical Science, with 58 
(5.12\%) publications and National Institute of Technology, with 50 (4.42\%) publications, got second and third rank, respectively. Publications from All India Institute of Medical Science received highest number of citations $(11,876)$ at a rate of 204.76 citations per publication, followed by Vellore Institute of Technology which received 5,481 citations at a rate of 140.54 citations per publication. Publications from these two institutes were highly used since 2013 (4,138 and 1,706 times, respectively). In top ten contributing organizations, authors affiliated to government organizations had written a greater number of publications on Road Traffic Accidents as compared to private organizations. Further, within top ten institutes, top five institutes (ranked from four to eight) were from South India. South Indian institutes' contribution to research on RTA was about one third of publications among the top ten contributing organizations.

\section{Key findings}

1. Out of 1,132 publications, 740 publications $(65.37 \%)$ were in the form of research articles, 361 publications $(31.82 \%)$ were in the form of conference proceedings, and 31 publications $(2.73 \%)$ were in the review form.

2. On an average 25.73 documents were published per year and received 392.95 citations per year.

3. Journal of Evaluation of Medical and Dental Sciences (JEMDS) published majority of the publications $(108,30.50 \%)$ and ranked first in the list of popular journals.

4. Highest number of times used keyword in these publications was Trauma (20\%).

5. Majority of the RTA publications (83.38\%) were written by the Indian authors individually or with local collaboration while low level of international collaboration was witnessed.

6. Majority of the publications $(1,081,95.49 \%)$ were written by multiple authors while 51 publications $(4.51 \%)$ were from single author. 
7. Most prolific authors were Tiwari, G. and Mohan, D. who topped the list with 18 publications each. They got 252 and 247 citations, respectively.

8. Authors affiliated to Indian Institute of Technology contributed to 120 publications (10.60\%) and thus stood at the first place.

\section{Conclusion}

In the light of the results of this study, we can conclude that interest of Indian authors in RTA research has improved due to which they contributed more publications during last decade. They were not much interested in writing review papers. The authors preferred to publish their research in local journals, but a small number of authors preferred to publish their research in high level international journals. We can also conclude that authors writing on RTA in India preferred working in teams at local level. However, for international collaboration they preferred authors in developed countries. The performance of government research institutions was much better than private research institutions.

\section{References}

Goli, S., Shruti, Siddiqui, M. Z., \& Gouda, J. (2018). High spending on hospitalised treatment: Road traffic accidents and injuries in India. Economic and Political Weekly, 53(14), 5260.

Lena, A., Sharma, Z., Zodge, T. K., Pranav, V., Malarout, N., D'souza, A., \& Kamath, S. (2019). Road traffic accidents: Development's collateral damage and a major public health and economic concern. Medico-Legal Update, 19(2), 302-306.

Murray, C. J., \& Lopez, A. D. (Eds.). (1996). The Global Burden of Disease: A Comprehensive Assessment of Morality and Disability from Diseases, Injuries and Risk Factors in 1990 and Projected to 2020. Boston: Harvard University Press. 
Pathak, A. G., Gadhari, R. K., Chaudhari, K. M., \& Devraj, N. A. (2018). Two years study of deaths due to vehicular accidents in North Maharashtra region. Indian Journal of Forensic Medicine and Toxicology, 12(1), 170-173.

Ruikar, M. (2013). National statistics of road traffic accidents in India. Journal of Orthopedics, Traumatology and Rehabilitation, 6(1), 1-6. https://doi.org/10.4103/0975-7341.118718

Shami, S. (2005). Road traffic safety: Cost of government neglect. Economic and Political Weekly, 40(16), 1598-1602.

Sharma, N., Bairwa, M., Gowthamghosh, B., Gupta, S. D., \& Mangal, D. K. (2018. A bibliometric analysis of the published road traffic injuries research in India, post-1990. Health Research Policy and Systems, 16(1), 1-11. https://doi.org/10.1186/s12961-0180298-9

Shobhana, S. S., Ravi Raj, K. G., Yadav, A., \& Kumar, L. R. (2019). Analysis of pattern of fatal head injuries in road traffic accidents. Medico - Legal Update, 19(1), 130-133.

Singh, S. K. (2009). Road traffic crashes: The scourge of UP's cities. Economic and Political Weekly, 44(48), 22-24.

Sundar, S., \& Ghate, A. T. (2013). Accidents and road safety: Not high on the government's agenda. Economic and Political Weekly, 48(48), 77-83.

World Health Organisation. (2004). World Report on Road Traffic Injury Prevention. Geneva: World Health Organisation.

World Health Organisation. (2013). Global Status Report on Road Safety. Geneva: World Health Organisation.

World Health Organisation. (2018). Global Status Report on Road Safety. Geneva: World Health Organisation. 